\title{
Association between polymorphisms in the promoter region of pri-miR-34b/c and risk of hepatocellular carcinoma
}

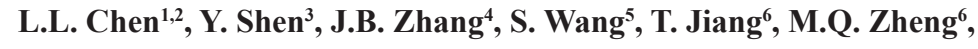
Z.J. Zheng ${ }^{7}$ and C.X. Chen ${ }^{1}$

${ }^{1}$ Department of Gastroenterology, The First Affiliated Hospital, Zhejiang University, Hangzhou, China

${ }^{2}$ Department of Gastroenterology, The First People's Hospital of Wenling, Wenling, China

${ }^{3}$ Department of Geriatrics, Zhongshan Hospital, Fudan University, Shanghai, China

${ }^{4}$ Liver Cancer Institute and Zhongshan Hospital, Fudan University, Shanghai, China

${ }^{5}$ Department of Cardiology, The First People's Hospital of Wenling, Wenling, China

${ }^{6}$ Central Laboratory, The First People's Hospital of Wenling, Wenling, China ${ }^{7}$ Department of Hepatobiliary Surgery, The First People's Hospital of Wenling, Wenling, China

Corresponding authors: Z.J. Zheng / C.X. Chen

E-mail: zhengzhijianz@163.com / chunxiachen66@sina.com

Genet. Mol. Res. 15 (4): gmr.15048723

Received April 25, 2016

Accepted August 1, 2016

Published October 5, 2016

DOI http://dx.doi.org/10.4238/gmr.15048723

Copyright (C) 2016 The Authors. This is an open-access article distributed under the terms of the Creative Commons Attribution ShareAlike (CC BY-SA) 4.0 License.

ABSTRACT. Hepatocellular carcinoma (HCC) is a major cause of cancer-related deaths worldwide. MicroRNA-34 (miR-34) gene plays a key role in altering the apoptotic cycle and pathways of downstream

Genetics and Molecular Research 15 (4): gmr.15048723 
cells, and therefore influences carcinogenesis. In this case-control study, we assessed the role of the pri-miR-34b/c rs4938723 polymorphism in HCC risk. The pri-miR-34b/c polymorphic genotype was determined in 286 patients with $\mathrm{HCC}$ and 572 controls using polymerase chain reaction-restriction fragment length polymorphism. The male gender $\left(\chi^{2}=12.95, \mathrm{P}<0.001\right)$, regular alcohol consumption $\left(\chi^{2}=16.81, \mathrm{P}\right.$ $<0.001)$, and a family history of cancer $\left(\chi^{2}=11.88, \mathrm{P}=0.001\right)$ were associated with HCC risk. However, the age $(t=1.19, \mathrm{P}=0.12)$ and tobacco smoking habit $\left(\chi^{2}=0.64, \mathrm{P}=0.42\right)$ of HCC patients were comparable to those of the controls. The TC (adjusted OR $=1.46$, $95 \% \mathrm{CI}=1.06-2.01)$ and $\mathrm{CC}$ (adjusted $\mathrm{OR}=3.07,95 \% \mathrm{CI}=1.77-5.34)$ genotypes of pri-miR-34b/c rs 4938723 were correlated with a higher risk of HCC compared to the TT genotype. Moreover, the TC+CC genotype was correlated with an increased risk of HCC compared to the TT genotype (adjusted $\mathrm{OR}=1.64,95 \% \mathrm{CI}=1.21-2.22$ ). In the recessive model, the CC genotype of pri-miR-34b/c rs4938723 was significantly correlated with an elevated risk of HCC compared to the TT+TC genotype (adjusted $\mathrm{OR}=2.50,95 \% \mathrm{CI}=1.49-4.22$ ). Further large-scale and multi-center studies are required to confirm these results.

Key words: pri-miR-34b/c; Polymorphism; Hepatocellular carcinoma

\section{INTRODUCTION}

Hepatocellular carcinoma (HCC) is a major cause of cancer-related deaths worldwide (IARC, 2012). The etiology of HCC has been widely studied; however, its actual mechanism is still unclear. The pathogenesis of HCC is influenced by a number of environmental factors, such as infection with hepatitis B virus and hepatitis $C$ virus, and lifestyle factors, such as long-term alcohol consumption, as well as contaminated water and aflatoxin consumption (Chitapanarux and Phornphutkul, 2015; de Martel et al., 2015; Kikuchi et al., 2015; Kubo et al., 2015). Therefore, hereditary factors may contribute to the development of HCC. Moreover, familial aggregation and co-aggregation of HCC have indicated that genetic factors play a major role in the development of HCC. Previous molecular studies have reported that genetic factors, such as the genes coding for human leukocyte antigen (HLA)-DRB1, FasL, epidermal growth factor, human serum antigen-miR-1269, cyclooxygenase-2, and methylene tetrahydrofolate reductase, play an essential role in HCC susceptibility (Shen et al., 2015; Wang et al., 2015; Xiong et al., 2015; Zhang et al., 2015; Khalifa et al., 2016; Ma et al., 2016).

Previous studies have revealed that miRNA contributes to the initiation, progression, metastasis, and drug resistance of HCC ( $\mathrm{Li}$ et al., 2015). Changes in microRNA-34 (miR34) expression could influence the expression of their downstream genes, thereby influencing carcinogenesis. $m i R-34 b$ and $m i R-34 c$ are homologous to $m i R-34$ (Guo et al., 2012). CpG is present upstream of the transcription start site of the pri-miR-34b/c CpG island (Guo et al., 2012). CpG island methylation has been reported to inhibit the activation of miR-34 via p53, thereby influencing cell proliferation and increasing the risk of carcinogenesis (Xu et al., 2011; Wang et al., 2014; Zhang et al., 2014b). So far, three studies have investigated the association

Genetics and Molecular Research 15 (4): gmr.15048723 
between polymorphisms in the promoter region of $m i R-34 b / c$ and $\mathrm{HCC}$ risk; however, the results of these studies are inconsistent (Xu et al., 2011; Han et al., 2013; Son et al., 2013). Moreover, these studies did not analyze the interaction between the pri-miR-34b/c rs 4938723 polymorphism and environmental factors in HCC risk. In this 1:2 matched case-control study, we have evaluated the possible role of the pri-miR-34b/c rs4938723 polymorphism in HCC risk, and its interaction with environmental factors in a Chinese population.

\section{MATERIAL AND METHODS}

\section{Patients}

A total of 286 patients with HCC were enrolled from the First People's Hospital of Wenling and Zhongshan Hospital of Shanghai between March 2013 and October 2015. HCC was confirmed in all patients via pathological examination. HCC patients with autoimmune hepatitis, drug-induced hepatitis, Wilson's disease, HIV infection, syphilis, or secondary or metastatic HCC were excluded from this study. A total of 572 controls were recruited from the Outpatient Clinics of our hospital and health examination center between March 2013 and October 2015. Individuals without a history of chronic or acute infectious disease, tumors, or end-stage kidney disease were included in this study.

The demographic and clinical variables of all HCC patients and control subjects were collected by a standard questionnaire or medical records. The clinical variables (TNM stage and Child-Pugh score) were collected from the patient medical records. Written informed consent was obtained from all patients with HCC and control subjects prior to the study. The study protocol was approved by the Ethics Committee of the First People's Hospital of Wenling.

\section{Genotyping}

Venous blood samples $(5 \mathrm{~mL})$ were obtained from all enrolled patients with $\mathrm{HCC}$ and control subjects. DNA was extracted from the venous blood samples using a Tiangen Blood DNA kit (Tiangen, Beijing, China). The pri-miR-34b/c rs4938723 polymorphism was genotyped by polymerase chain reaction-restriction fragment length polymorphism (PCR-RFLP) using the primers (5'-CTCTGGGAACCTTCTTTGACCCAT-3' and 5'-TGAGATCAAGGCC ATACCATTCAAGA-3') designed by Sangon Biological Engineering Ltd. (Shanghai, China). The PCR products were digested using the $B c c$ I restriction enzyme (Sangon Biological Engineering Ltd.). The thermal cycling program for porous PCR (MJ Research Inc., Waltham, MA, USA) was as follows: initial denaturation at $94^{\circ} \mathrm{C}$ for $5 \mathrm{~min} ; 35$ cycles of denaturation at $94^{\circ} \mathrm{C}$ for $45 \mathrm{~s}$, annealing at $63^{\circ} \mathrm{C}$ for $45 \mathrm{~s}$, and extension at $72^{\circ} \mathrm{C}$ for $45 \mathrm{~s}$; and a final extension at $72^{\circ} \mathrm{C}$ for $5 \mathrm{~min}$. For quality control, $10 \%$ of the samples were randomly genotyped again and sequenced to validate the RFLP findings.

\section{Statistical analysis}

The demographic, lifestyle, and clinical variables were compared between the case and control groups by the chi-square test or student $t$-test. The genotype frequencies of the pri$m i R-34 b / c$ rs 4938723 polymorphism were compared between the HCC patients and controls

Genetics and Molecular Research 15 (4): gmr.15048723 
using the chi-square test. Deviation of the HCC patients and control individuals from the Hardy-Weinberg equilibrium (HWE) was calculated by the chi-square test. The odds ratios (ORs) and 95\% confidence intervals $(95 \% \mathrm{CI})$ associated with $\mathrm{HCC}$ risk were determined by logistic regression analysis, taking the control individuals as the reference group. The association between the pri-miR-34b/c rs4938723 polymorphism and risk of HCC were analyzed by the co-dominant, dominant, and recessive models. All statistical analyses were performed using the SPSS v.20.0 software package (SPSS Inc., Chicago, IL, USA). The differences were considered to be statistically significant at $\mathrm{P}$ values $<0.05$.

\section{RESULTS}

The demographic and clinical variables of investigated subjects are summarized in Table 1. The mean ages of HCC patients and controls were $61.42 \pm 10.67$ and $60.45 \pm 11.47$ years, respectively. The male gender $\left(\chi^{2}=12.95, \mathrm{P}<0.001\right)$, regular alcohol consumption $\left(\chi^{2}\right.$ $=16.81, \mathrm{P}<0.001)$, and a family history of cancer $\left(\chi^{2}=11.88, \mathrm{P}=0.001\right)$ were associated with HCC risk. However, the age $(t=1.19, \mathrm{P}=0.12)$ and tobacco smoking habit $\left(\chi^{2}=0.64, \mathrm{P}\right.$ $=0.42)$ of HCC patients were comparable to those of the controls. Ninety-eight of the included HCC patients (34.27\%) presented TNM stage I-II, and the remaining $188(65.73 \%)$ presented TNM stage III-IV. Sixty-one (21.33\%), 121 (42.41\%), and $104(36.36 \%)$ of the cases presented a Child-Pugh score of A, B, and C, respectively.

Table 1. Demographic and clinical variables of included patients and controls.

\begin{tabular}{|c|c|c|c|c|c|c|}
\hline Variables & Patients $(\mathrm{N}=286)$ & $\%$ & Controls $(\mathrm{N}=572)$ & $\%$ & $\chi^{2}$ test or $t$-test & P value \\
\hline Age (years) & $61.42 \pm 10.67$ & & $60.45 \pm 11.47$ & & 1.19 & 0.12 \\
\hline \multicolumn{7}{|l|}{ Gender } \\
\hline Females & 204 & 71.33 & 336 & 58.74 & & \\
\hline Males & 82 & 28.67 & 236 & 41.26 & 12.95 & $<0.001$ \\
\hline \multicolumn{7}{|c|}{ Tobacco smoking } \\
\hline Never & 176 & 61.54 & 368 & 64.34 & & \\
\hline Ever & 110 & 38.46 & 204 & 35.66 & 0.64 & 0.42 \\
\hline \multicolumn{7}{|c|}{ Alcohol consumption } \\
\hline Never & 136 & 47.55 & 356 & 62.24 & & \\
\hline Ever & 150 & 52.45 & 216 & 37.76 & 16.81 & $<0.001$ \\
\hline \multicolumn{7}{|c|}{ Family history of cancer } \\
\hline No & 264 & 92.31 & 557 & 97.38 & & \\
\hline Yes & 22 & 7.69 & 15 & 2.62 & 11.88 & 0.001 \\
\hline \multicolumn{7}{|l|}{ TNM stage } \\
\hline I-II & 98 & 34.27 & & & & \\
\hline III-IV & 188 & 65.73 & & & & \\
\hline \multicolumn{7}{|c|}{ Child-Pugh classification } \\
\hline $\mathrm{A}$ & 61 & 21.33 & & & & \\
\hline $\mathrm{B}$ & 121 & 42.31 & & & & \\
\hline $\mathrm{C}$ & 104 & 36.36 & & & & \\
\hline
\end{tabular}

The genotype frequencies of the pri-miR-34b/c rs4938723 polymorphism in HCC patients and controls are summarized in Table 2; 102 (35.66\%), $146(51.05 \%)$, and $38(13.29 \%)$ patients with HCC and 272 (47.55\%), 267 (46.68\%), and 33 (5.77\%) control subjects expressed the TT, TC, and CC genotypes, respectively. We observed significant differences in the genotype frequencies of the pri-miR-34b/c rs4938723 polymorphism between HCC patients and controls $\left(\chi^{2}=19.96, \mathrm{P}<0.001\right)$. The distributions of the pri-miR-34b/c rs4938723 TT, TC, and CC genotypes conformed to the HWE in patients, and deviated from the HWE in controls. 
Table 2. Genotype distributions of the pri-miR-34b/c rs4938723 polymorphism in hepatocellular carcinoma (HCC) patients and controls.

\begin{tabular}{|c|c|c|c|c|c|c|c|c|c|c|}
\hline \multirow[t]{2}{*}{ Genotypes } & \multirow[t]{2}{*}{ Patients $(\mathrm{N}=286)$} & \multirow[t]{2}{*}{$\%$} & \multirow[t]{2}{*}{ Controls $(\mathrm{N}=572)$} & \multirow[t]{2}{*}{$\%$} & \multirow[t]{2}{*}{$\chi^{2}$ test } & \multirow[t]{2}{*}{$P$ value } & \multicolumn{2}{|c|}{ HWE for patients } & \multicolumn{2}{|c|}{ HWE for controls } \\
\hline & & & & & & & $\chi^{2}$ test & $P$ value & $\chi^{2}$ test & $P$ value \\
\hline TT & 102 & 35.66 & 272 & 47.55 & & & & & & \\
\hline $\mathrm{TC}$ & 146 & 51.05 & 267 & 46.68 & & & & & & \\
\hline $\mathrm{CC}$ & 38 & 13.29 & 33 & 5.77 & 19.96 & $<0.001$ & 1.60 & 0.21 & 75.81 & $<0.001$ \\
\hline
\end{tabular}

HWE, Hardy-Weinberg equilibrium.

We then analyzed the association between the $p r i-m i R-34 b / c$ polymorphism and HCC risk (Table 3). Conditional logistic regression analysis indicated that the TC and $\mathrm{CC}$ genotypes

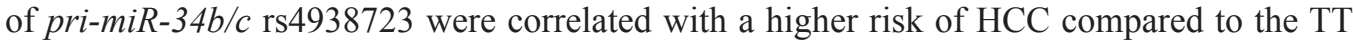
genotype (TC genotype: adjusted $\mathrm{OR}=1.46,95 \% \mathrm{CI}=1.06-2.01$ and $\mathrm{CC}$ genotype: adjusted $\mathrm{OR}=3.07,95 \% \mathrm{CI}=1.77-5.34$ ). Moreover, the $\mathrm{TC}+\mathrm{CC}$ genotype of $p r i-m i R-34 b / c$ rs 4938723 was correlated with an increased risk of HCC compared to the TT genotype (adjusted OR $=1.64,95 \% \mathrm{CI}=1.21-2.22)$. In the recessive model, the CC genotype of pri-miR-34b/c rs4938723 was significantly correlated with an elevated risk of HCC, compared to the TT+TC genotype (adjusted $\mathrm{OR}=2.50,95 \% \mathrm{CI}=1.49-4.22$ ).

Table 3. Association between the pri-miR-34b/c rs4938723 polymorphism and risk of hepatocellular carcinoma (HCC).

\begin{tabular}{l|c|c|c|c|c|c}
\hline Genotypes & Patients $(\mathrm{N}=286)$ & $\%$ & Controls $(\mathrm{N}=572)$ & $\%$ & Adjusted OR $(95 \% \mathrm{CI})^{1}$ & P value \\
\hline Co-dominant & & & & & & \\
\hline TT & 102 & 35.66 & 272 & 47.55 & 1.0 (Ref.) & - \\
\hline TC & 146 & 51.05 & 267 & 46.68 & $1.46(1.06-2.01)$ & 0.01 \\
\hline CC & 38 & 13.29 & 33 & 5.77 & $3.07(1.77-5.34)$ & $<0.001$ \\
\hline Dominant & & & & & & \\
\hline TT & 102 & 35.66 & 272 & 47.55 & 1.0 (Ref.) & - \\
\hline TC+CC & 184 & 64.34 & 300 & 52.45 & $1.64(1.21-2.22)$ & 0.001 \\
\hline Recessive & & & & & & \\
\hline TT+TC & 248 & 86.71 & 539 & 94.23 & 1.0 (Ref.) & - \\
\hline CC & 38 & 13.29 & 33 & 5.77 & $2.50(1.49-4.22)$ & $<0.001$ \\
\hline
\end{tabular}

${ }^{1}$ Adjusted for age, gender, tobacco smoking, alcohol consumption, and family history of cancer. OR, odds ratio; $\mathrm{CI}$, confidence interval.

\section{DISCUSSION}

Recently, genomic susceptibility to diseases has attracted a considerable amount of attention. In this study, we observed that individuals harboring the TC and $\mathrm{CC}$ genotypes of pri-miR-34b/c were at a higher risk of HCC than those expressing the TT genotype.

The pri-miR-34b/c rs4938723 polymorphism is known to be located at the core promoter region of pri-miR-34b/c. Changes in the expression of $m i R-34$ could influence the expression of the downstream gene, as $m i R-34$ is a key gene regulating the cell cycle and apoptotic pathways of downstream cells. The rs4938723 polymorphism has been shown to influence the cell cycle of downstream cells, as well as induce changes in the expression of key genes in the apoptotic pathway, thereby influencing cancer susceptibility. Several studies have reported a significant association between the rs 4938723 polymorphism and risk of malignant tumors such as acute lymphoblastic leukemia, cervical cancer, papillary thyroid carcinoma, 
gastric cancer, esophageal squamous cell carcinoma, renal cell cancer, and colorectal cancer (Oh et al., 2014; Zhang et al., 2014a,b; Chen et al., 2015; Pan et al., 2015; Tong et al., 2016; Yuan et al., 2016). A previous large-scale case-control study comprising 1109 esophageal squamous cell carcinoma patients and 1275 healthy subjects reported a correlation between the GG genotype of $\mathrm{miR}-34 \mathrm{~b} / \mathrm{c}$ and a significantly reduced risk of esophageal squamous cell carcinoma in a Chinese population (Zhang et al., 2014a). Additionally, the C allele of pri-miR-34b/c rs4938723 was shown to be associated with an increased risk of renal cell cancer (RCC) in a Chinese population in a case-control study comprising 710 RCC patients and 760 controls (Zhang et al., 2014b). Tong et al. (2016) revealed a correlation between the pri-miR-34b/c polymorphisms and risk of developing childhood acute lymphoblastic leukemia by influencing the transcription activity of the $\mathrm{pri}-\mathrm{miR}-34 \mathrm{~b} / \mathrm{c}$ promoter in Chinese acute lymphoblastic leukemia patients. On the other hand, Yuan et al. (2016) reported that the pri-miR-34b/c rs4938723 polymorphism could play an important role in the pathogenesis of cervical cancer, based on the results of a hospital based case-control study with 328 cervical cancer patients and 568 healthy subjects. Chen et al. (2015), who analyzed 784 patients with papillary thyroid carcinoma and 1006 healthy controls, reported a correlation between the pri-miR-34b/c rs4938723 polymorphism and the risk of developing papillary thyroid carcinoma. Pan et al. (2015), in a study with 197 gastric cancer patients and 289 controls, reported the possible role of pri-miR-34b/c rs4938723 in gastric

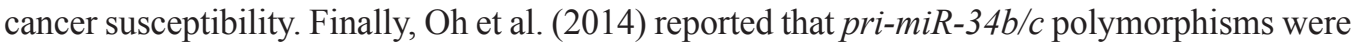
associated with a reduced risk of colorectal cancer, based on the results of a study conducted in 545 colorectal cancer patients and 428 healthy controls. So far, three previous studies

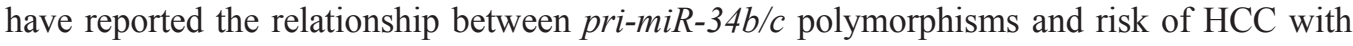
inconsistent results (Xu et al., 2011; Han et al., 2013; Son et al., 2013). Xu et al. (2011) reported a positive correlation between the TC and CC genotypes of pri-miR-34b/c and HCC risk in 501 HCC patients and 548 cancer-free controls. Han et al. (2013) observed a significant positive association between the CC genotype of pri-miR-34b/c rs4938723 and HCC risk in a largescale study conducted in a Chinese population. Additionally, in a study conducted in 157 HCC patients and 201 cancer-free control subjects, Son et al. (2013) discovered that the loss of the T allele in pri-miR-34b/c could increase the risk of HCC in a Korean population. In our study, we observed a positive correlation between the pri-miR-34b/c polymorphism and risk of $\mathrm{HCC}$ in a Chinese population in all genetic models.

The results of our study are subject to two limitations. Firstly, the HCC patients and control subjects were selected from two hospitals; therefore, the sample population did not represent the overall population. Secondly, other genetic polymorphisms in miRNA may interact with pri-miR-34b/c, which may induce bias in our study. In conclusion, we discovered that the $p r i-m i R-34 b / c$ rs 4938723 polymorphism is positively correlated with HCC development in the Chinese population of east coastal areas.

\section{Conflicts of interest}

The authors declare no conflicts of interest.

\section{ACKNOWLEDGMENTS}

Research supported by funds provided by the Scientific and Technological Project of Wenling (\#2014C311042). 


\section{REFERENCES}

Chen P, Sun R, Pu Y, Bai P, et al. (2015). Pri-Mir-34b/C and Tp-53 polymorphisms are associated with the susceptibility of papillary thyroid carcinoma: a case-control study. Medicine (Baltimore) 94: e1536. http://dx.doi.org/10.1097/ $\underline{\text { MD. } 0000000000001536}$

Chitapanarux T and Phornphutkul K (2015). Risk factors for the development of hepatocellular carcinoma in Thailand. $J$ Clin Transl Hepatol 3: 182-188. http://dx.doi.org/10.14218/JCTH.2015.000025

de Martel C, Maucort-Boulch D, Plummer M and Franceschi S (2015). World-wide relative contribution of hepatitis B and C viruses in hepatocellular carcinoma. Hepatology 62: 1190-1200. http://dx.doi.org/10.1002/hep.27969

Guo Z, Wu C, Wang X, Wang C, et al. (2012). A polymorphism at the miR-502 binding site in the $3 \phi$-untranslated region of the histone methyltransferase SET8 is associated with hepatocellular carcinoma outcome. Int. J. Cancer 131: 1318-1322. http://dx.doi.org/10.1002/ijc.27352

Han Y, Pu R, Han X, Zhao J, et al. (2013). Associations of pri-miR-34b/c and pre-miR-196a2 polymorphisms and their multiplicative interactions with hepatitis B virus mutations with hepatocellular carcinoma risk. PLoS One 8: e58564. http://dx.doi.org/10.1371/journal.pone.0058564

International Agency for Research on Cancer (2012). GLOBOCAN 2012: Estimated cancer incidence, mortality and prevalence worldwide in 2012. http://globocan.iarc.fr/Pages/fact sheets_population.aspx. Accessed June 1, 2016.

Khalifa RH, Bahgat DM, Darwish HA and Shahin RM (2016). Significant association between FasL gene -844T/C polymorphism and risk to hepatocellular carcinoma in Egyptian patients. Immunol. Lett. 172: 84-88. http://dx.doi. org/10.1016/j.imlet.2016.02.007

Kikuchi M, Horie Y, Ebinuma H, Taniki N, et al. (2015). Alcoholic liver cirrhosis and significant risk factors for the development of alcohol-related hepatocellular carcinoma - Japan, 2012. Nihon Arukoru Yakubutsu Igakkai Zasshi 50: $222-234$

Kubo S, Takemura S, Tanaka S, Shinkawa H, et al. (2015). Management of hepatitis B virus infection during treatment for hepatitis B virus-related hepatocellular carcinoma. World J. Gastroenterol. 21: 8249-8255. http://dx.doi.org/10.3748/ wjg.v21.i27.8249

Li T, Xie J, Shen C, Cheng D, et al. (2015). Amplification of Long Noncoding RNA ZFAS1 Promotes Metastasis in Hepatocellular Carcinoma. Cancer Res. 75: 3181-3191. http://dx.doi.org/10.1158/0008-5472.CAN-14-3721

Ma S, Wu J, Wu J, Wei Y, et al. (2016). Relationship between HLA-DRB1 allele polymorphisms and familial aggregations of hepatocellular carcinoma. Curr. Oncol. 23: e1-e7. http://dx.doi.org/10.3747/co.23.2839

Oh J, Kim JW, Lee BE, Jang MJ, et al. (2014). Polymorphisms of the pri-miR-34b/c promoter and TP53 codon 72 are associated with risk of colorectal cancer. Oncol. Rep. 31: 995-1002.

Pan XM, Sun RF, Li ZH, Guo XM, et al. (2015). Pri-miR-34b/c rs4938723 polymorphism is associated with a decreased risk of gastric cancer. Genet. Test. Mol. Biomarkers 19: 198-202. http://dx.doi.org/10.1089/gtmb.2014.0287

Shen XF, Zeng XT, Jian ZY, Zhou M, et al. (2015). Quantitative assessment of the effect of epidermal growth factor 61A/G polymorphism on the risk of hepatocellular carcinoma. Oncol. Lett. 10: 3199-3205.

Son MS, Jang MJ, Jeon YJ, Kim WH, et al. (2013). Promoter polymorphisms of pri-miR-34b/c are associated with hepatocellular carcinoma. Gene 524: 156-160. http://dx.doi.org/10.1016/j.gene.2013.04.042

Tong N, Chu H, Wang M, Xue Y, et al. (2016). Pri-miR-34b/c rs4938723 polymorphism contributes to acute lymphoblastic leukemia susceptibility in Chinese children. Leuk. Lymphoma 57: 1436-1441. http://dx.doi.org/10.3109/10428194. $\underline{2015.1092528}$

Wang X, Lu X, Fang Y, Chen H, et al. (2014). Association between miR34b/c polymorphism rs4938723 and cancer risk: a meta-analysis of 11 studies including 6169 cases and 6337 controls. Med. Sci. Monit. 20: 1977-1982. http://dx.doi. org/10.12659/MSM.892350

Wang Y, Jiang H, Liu T, Tang W, et al. (2015). Cyclooxygenase-2 -1195G>A (rs689466) polymorphism and cancer susceptibility: an updated meta-analysis involving 50,672 subjects. Int. J. Clin. Exp. Med. 8: 12448-12462.

Xiong G, Wang Y, Ding Q and Yang L (2015). Hsa-mir-1269 genetic variant contributes to hepatocellular carcinoma susceptibility through affecting SOX6. Am. J. Transl. Res. 7: 2091-2098.

Xu Y, Liu L, Liu J, Zhang Y, et al. (2011). A potentially functional polymorphism in the promoter region of miR-34b/c is associated with an increased risk for primary hepatocellular carcinoma. Int. J. Cancer 128: 412-417. http://dx.doi. org/10.1002/ijc. 25342

Yuan F, Sun R, Chen P, Liang Y, et al. (2016). Combined analysis of pri-miR-34b/c rs4938723 and TP53 Arg72Pro with cervical cancer risk. Tumour Biol. 37: 6267-6273. http://dx.doi.org/10.1007/s13277-015-4467-y

Zhang H, Li G and Zhang Z (2015). Association between MTHFR A1298C polymorphism and hepatocellular carcinoma risk. Int. J. Clin. Exp. Med. 8: 9135-9141.

Genetics and Molecular Research 15 (4): gmr.15048723 
Zhang J, Huang X, Xiao J, Yang Y, et al. (2014a). Pri-miR-124 rs531564 and pri-miR-34b/c rs4938723 polymorphisms are associated with decreased risk of esophageal squamous cell carcinoma in Chinese populations. PLoS One 9: e100055. http://dx.doi.org/10.1371/journal.pone.0100055

Zhang S, Qian J, Cao Q, Li P, et al. (2014b). A potentially functional polymorphism in the promoter region of miR-34b/c is associated with renal cell cancer risk in a Chinese population. Mutagenesis 29: 149-154. http://dx.doi.org/10.1093/ mutage/geu001

Genetics and Molecular Research 15 (4): gmr.15048723 